\title{
A case of May-Thurner Syndrome: An old anomaly but, a new suggestion: A case report
} \section{Arslan ${ }^{1}$, Zeynep Cerit ${ }^{2}$, Özgür İlker Koska ${ }^{3}$, Sema Aydoğdu}

Şule Gökçe ${ }^{1}$ *, Gülsüm Keskin ${ }^{1}$, Şeyma Kar Yaşar ${ }^{1}$, Aylin Tuğba

1. Ege University Faculty of Medicine, Department of Pediatrics, General Pediatrics Unit. Ege University, Bornova, 35040, Izmir, Turkey

2. Near East University, Department of Pediatric Cardiology, Nicosia, Cyprus.

3. Ege University Faculty of Medicine, Department of Radiology, Ege University, Bornova, 35040, Izmir, Turke

4.Professor Doctor, Ege University Faculty of Medicine, Department of Pediatrics, Ege University, Bornova,
Date Received: 09-Mar-2018 Revision Received: 13-Jun-2018 Date Accepted: 03-Jul-2018

\section{Correspondence: Şule Gökçe} (sule.gokce@ege.edu.tr)

\begin{abstract}
May-Thurner syndrome (MTS) is an anatomical condition resulting in compression of the left common iliac vein between the right common iliac artery and the underlying spine. MTS is rarely diagnosed because diagnostic workup is seldom continued once the diagnosis of a deep vein thrombosis (DVT) has been established. Furthermore, patients with DVT generally have several well-known confounding risk factors. We report a 16-year-old girl with a history of left leg swelling who was incidentally diagnosed with MTS. We hope that our case report will create awareness of vascular abnormalities in sports medicine and suggest that routine venous Doppler ultrasound screening may help to detect MTS or associated anatomical prior to the formation of early thrombosis.
\end{abstract}

Keywords: May-Thurner syndrome, deep vein thrombosis, sports medicine

\section{Introduction}

May-Thurner syndrome (MTS) also referred to as iliac vein compression syndrome, iliocaval compression syndrome and Cockett syndrome, is a rare condition that is caused by the left iliac vein undergoing compression by the right iliac artery against the fifth lumbar vertebra, thus increasing the risk of deep vein thrombosis (DVT) in the left lower extremity. MTS commonly affects females with a mean age of 40 years; however, the exact incidence and prevalence are unknown because the anatomical features of this condition are not associated with specific symptoms until thrombosis occurs ${ }^{1}$. The frequency of the disease is estimated to range from 2 to $5 \%$ of patients who present with symptomatic venous disorder in the lower extremities ${ }^{2}$. The clinical manifestations of this syndrome include swelling of the lower extremities, venous claudication, recurrent superficial vein thrombosis or other symptoms and signs of moderate-to-severe chronic venous insufficiency; for example, hyperpigmentation and venous ulceration ${ }^{3,4}$. However, these symptoms are only evident as venous system compression progresses. Therefore, the clinical diagnosis of MTS is based on clinical presentation and suspicion. The literature shows that MTS is generally reported in adults. Only two previous studies have described this syndrome in teenagers ${ }^{5,6}$. Here, we report a case of MTS in a young female athlete who was diagnosed incidentally

\section{Case description}

A 16-year-old female basketball player presented to our clinic with a 10-day history of slight swelling in the left leg. We did not discover anything relevant from her past medical history. She had had no previous surgical interventions and no constitutional symptoms. There was no history of contact with sick individuals, recent travel, trauma, fever, or chills except for a little swelling which rarely occurred on her left lower extremity after training, althouhg this improved with leg elevation. There was no known family history of venous thrombosis. She did not have a history of previous clotting problems nor was there a clotting problem in the family. Results of routine haematological and biochemical laboratory tests were within normal reference ranges, including erythrocyte sedimentation rate, C-reactive protein (CRP) and serum total proteins, albumin and immunoglobulins. On the second day of clinical followup, her physical examination findings showed a severe swelling of the left leg but without severe pain. Posterior tibial and dorsalis pedis pulses were evident with good capillary refills. Her right lower extremity was unremarkable. A lower extremity venous colour Doppler ultrasound was performed to evaluate whether there was an acute thrombus of the left common femoral, popliteal, and gastrocnemius veins; this scan was negative (Figure 1). The ultrasound revealed compression of the left iliac vein by the iliac artery, consistent with MTS. The patient was subsequently referred to the interventional radiology department for a left iliac venous angioplasty/stenting to prevent further mechanical compression that could lead to DVT, chronic thrombotic occlusion, or other venous compression complications. A venous stent was not implanted because there was no thrombus. Since the ultrasound clearly indicated MTS, the radiologist suggested that there was no need for venography. The patient was advised to use compression stockings until angioplasty/stenting and not to take oral contraceptives. She was then discharged. 


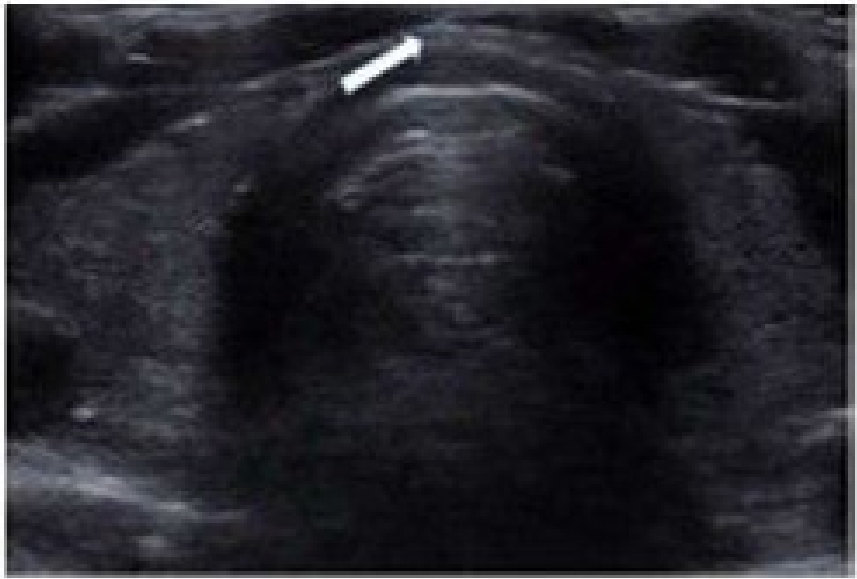

Venous Doppler ultrasonography images of lower extremity demostrating May-Thirner syndrome anatomy with compression of the left iliac vein via the right common iliac artery

\section{Discussion}

In this case report, we described a patient who was diagnosed with mild symptomatic MTS, a condition which was first described by May and Thurner in 19577 characterized by an intimal or endothelial spur in the common iliac vein (CIV) associated with the right iliac artery compressing the left iliac vein against the fifth lumbar vertebra ${ }^{8}$. In 1965, Cockett and Thomas ${ }^{9}$ determined a clinical syndrome in a subgroup of 29 patients with preponderate thrombosis in the left lower extremities. In the subsequent publications, the clinical condition resulting from pelvic and venous hypertension in the lower extremities was referred to as MTS, Cockett syndrome, iliac compression syndrome, and iliocaval compression syndrome.

The common presentation of MTS is acute pain and swelling of the left lower extremities $(18-49 \%$ of cases) related to venous hypertension, with or without DVT. Goldman et al. ${ }^{10}$ evaluated, 10 patients from 1998 to 2015; these authors reported that four patients had non-thrombotic MTS and $60 \%$ of all patients had presented with acute pain and swelling in the left lower extremity. Other common symptoms of MTS are generally related to venous compression and/ or obstruction, including venous claudication, recurrent superficial vein thrombosis, and signs of moderate-tosevere chronic venous insufficiency (e.g., hyperpigmentation and venous ulceration). In our case, there was no evidence of DVT in the patient's left leg. Furthermore, laboratory findings were not indicateive of any risk factors, including a postpartum or multiparous status, using oral contraceptives, or suffering from scoliosis, dehydration, and hypercoagulable disorders. The only known risk factor was the patient was female.

The diagnosis of MTS can be achieved by carrying out a detailed history and evaluation of the clinical features and initial diagnostic testing in female patients who present with acute unilateral limb swelling. There are no specific diagnostic markers for blood investigations. The most commonly used non-invasive and cost-effective modality for the diagnosis of DVT is Doppler ultrasonography however, this technique has limitations when evaluating iliac veins due to their deep pelvic location. Sonographic findings of the common femoral vein (CFV) can often suggest proximal obstruction. Loss of CFV collapsibility, a lack of respiratory variations, and the absence of a response to the Valsalva manoeuver even in the absence of CFV thrombosis, can be suggestive of a potential proximal compression or obstruction $^{11}$. Retroperitoneal pelvic venous structures can be demonstrated by cross-sectional venography with computed tomography and magnetic resonance venography, with excellent sensitivity and specificity. Digital subtraction venography remains the gold standard for the diagnosis of MTS. Typical findings include the reversal of flow within the left internal iliac vein and collateral formation. MTS may be suspected after evaluating the differential diagnosis for other illnesses such as DVT without extrinsic venous compression, other vascular causes of extremity swelling (e.g., unilateral peripheral lymphedema), pelvic mass, or aortoiliac aneurysm. When a female patient has a unilateral swelling in the left lower extremity, the initial diagnostic test should be a colour venous Doppler ultrasound to rule out DVT. Ultrasound allows for a correct evaluation of the DVT of the extremity if visualisation of the CIV is possible. On admission, our patient had mild clinical features for MTS, but on day two, she suffered acute swelling of the unilateral lower extremity. We did not know which factors caused the abrupt appearance of swelling in her left lower extremity in our clinic, but we hypothesised that this was due to compression of the left iliac vein undergoing progression. This was coincidental; we believe that this diagnosis is fortunate for our patient who is a basketball player because this anatomical abnormality increases the risk of DVT. We also believe that the early detection of MTS could prevent life-threatening events such as pulmonary embolism.

When MTS is symptomatic, it is necessary to begin therapy fot DVT, which is the most common presentation of MTS; such therapy might begin with thromboreductin ${ }^{2}$. Endovascular treatment is also common for the treatment of MTS, including stents and balloon venoplasty; these techniques aim to prevent early post-procedure rethrombosis, and prevent post-thrombotic syndrome. For example, O'Sullivan et al. reported the use of stents to treat compression of the iliac vein in their patients ${ }^{12}$. The stents normally used in this procedure are commonly between 12 and $16 \mathrm{~mm}$ in diameter in adults; the smallest diameter used for adults might be appropriate for a child aged 16 year $^{13}$. Stent size is determined by measuring the diameter of the patent distal CIV. A previous Turkish study carried out Bozkaya et al. reported that endovascular treatment of MTS was safe and effective in 21 symptomatic MTS patients with DVT; in this previous study, the stents were implemented 1-2 $\mathrm{cm}$ into the CIV when the lesion was placed less than $2 \mathrm{~cm}$ from the orifice of the left $\mathrm{CIV}^{14}$. However, stent diameter, and the difference in size between the vessel diameter and stent size, were not associated with symptomatic relief or complications ${ }^{15-16}$. The optimal stent size remains unknown but should be matched to the normal caliber of the vessel at a minimum. Sedhai et al. reported that the normal caliber of the iliac vessel outflow tract is not easily determinable by direct measurement but recommed that stent diameter should be $16-18 \mathrm{~mm}$ for the CIV. ${ }^{11}$ Other authors have also suggested that patients with MTS associated with DVT should also undergo CIV filter placement ${ }^{3}$.

\section{Conclusion}

In this case report, we describe the case of a 16-year-old female with MTS which was diagnosed incidentally. In sports medicine, athletes are usually routinely assessed for cardiac pathologies and biochemical anomalies. Because MTS is an asymptomatic anatomical vascular abnormality, physicians 
should consider this condition in young girls before they take up sporting activities, particulary those who are likely to be taking oral contraceptives, have the possibility of peripartum, or who have disorders in the coagulation pathway. Our case clearly showed that preliminary examination is not sufficient to determine the venous anomalies that may lead to thrombosis in sports medicine. We hope that our case report will create awareness for vascular abnormalities in sports medicine and, suggest that routine venous Doppler ultrasound screening may help to detect MTS, or the anatomical features associated with MTS prior to the formation of early thrombosis.

\section{Funding}

This work received no specific grant from any funding agency, commercial or not-for-profit sectors.

\section{Competing interests}

None.

\section{Authors' contributions}

Concept- Ş.G., G.K., S..Y., A.T.A., Z.C., Ö.İ.K., S.A.; DesignS..G., G.K., S.Y., A.T.A., Z.C., Ö.I.K., S.A.; Supervision - S..G., G.K., Ş.Y., A.T.A., Z.C., Ö.İ.K., S.A.; Materials S..G., G.K., Ş.Y., A.T.A., Z.C., Ö.İ.K., S.A.; Data Collection and/or Processing - Ş.G., Ö.İ.K., S.A.; Analysis and/or Interpretation - S..G., G.K., Ş.Y., A.T.A., Z.C., Ö.I.K., S.A.; Literature Review- Ş.G., F.K.; Writing - Ş.G., Z.C.; Critical Review -Ö.İ.K., S.A.

\section{Ethical standards}

Informed consent was provided by the patient's parent/ guardian.

\section{References}

1. Lee KM, Park JK, Lim SH, Cho KR, Kim YH, Cheong SH. MayThurner syndrome found incidentally after left femoral catheterization in a pediatric patient. Pediatr Blood Cancer. 2010;55(6):1191 -4. DOI: $10.1002 / \mathrm{pbc} .22595$.

2. Birn J, Vedantham S. May-Thurner syndrome and other obstructive iliac vein lesions: meaning, myth, and mystery. Vasc Med. 2015;20(1):74-83. DOI: 10.1177/1358863X14560429.

3. Moudgil N, Hager E, Gonsalves C, Larson R, Lombardi J, DiMuzio P. May-Thurner syndrome: case report and review of the literature involving modern endovascular therapy. Vascular. 2009;17(6):330-5. DOI: $10.2310 / 6670.2009 .00027$.

4. Delis KT, Bountouroglou D, Mansfield AO. Venous claudication in iliofemoral thrombosis: long-term effects on venous hemodynamics, clinical status, and quality of life. Ann Surg. 2004;239(1):118-26. DOI: 10.1097/01.sla.0000103067.10695.74.
5. Raffini L, Raybagkar D, Cahill AM, Kaye R, Blumenstein M, Manno C. May-Thurner syndrome (iliac vein compression) and thrombosis in adolescents. Pediatr Blood Cancer. 2006;47(6):834-8. DOI: 10.1002/ pbc.20728.

6. Vyas S, Roberti I, McCarthy C. May-Thurner syndrome in a pediatric renal transplant recipient--case report and literature review. Pediatr Transplant. 2008;12(6):708-10. DOI: 10.1111/j.13993046.2008.00941.x.

7. May R, Thurner J. The cause of the predominately sinistral occurrence of thrombosisof the pelvic veins. Angiology. 1957;8(5):419-427. DOI: 10,1177/000331975700800505.

8. Petrin Z, Wowkanech C, Sinha AN, Gupta S, Patel MK. Female runner with painful left thigh swelling: A case of May-Thurner syndrome. PM R. 2018; 10(2):227-229. DOI:10.1006/j.pmrj.2017.06.016.

9. Cockett FB, Thomas ML. The iliac compression syndrome. Br J Surg. 1965;52(5543):816-821.

10. Goldman RE, Arendt VA, Kothary N, Kuo WT, Sze DY, Hofmann $\mathrm{LV}$, et al. Endovascular management of May-Thurner syndrome in adolescents: A single-center experience. J Vasc Interv Radiol. 2017;28(1):71-77. DOI: 10.1016/j.jvir.2016.09.005.

11. Sedhai YR., GolamariR, Salei A, Alukal J, Basnyat S, Pathak S, et al. May-Thurner syndrome. Am J Med Sci. 2018;355(5): 510-514. DOI: 10.1016 /j.amjms.2017.09.011.

12. O’Sullivan GJ, Semba CP, Bittner CA, Kee ST, Razavi MK, Sze DY, et al. Endovascular management of iliac vein compression (MayThurner) syndrome. J Vasc Interv Radiol. 2000;11(7):823-836.

13. Oguzkurt L, Tercan F, Sener. M. Successful endovascular treatment of 1 liac vein compression (May-Thurner) syndrome in a pediatric patient. Cardiovasc Intervent Radiol. 2006;29(3):446-449. DOI: 10.1007/s00270-004-0247.

14. Bozkaya H, Cinar C, Ertugay S, Korkmaz M, Guneyli S, Posacıŏlu $\mathrm{H}$, et al. Endovascular treatment of iliac vein compression (MayThurner) syndrome: Angioplasty and Stenting with or without Manual Aspiration Thrombectomy and Catheter-Directed Thrombolysis. Ann Vasc Dis. 2015;8(1):21-28. DOI:10.3400/avd.oa.14-00110.

15. Raju S, Neglen P. High prevalence of non thrombotic iliac vein lesions in chronic venous disease: A permissive role in pathogenicity. J Vasc Surg. 2006;44(1):136-143. DOI: 10.1016 / j.jvs.2006.02.065.

16. Raju S, Buck WJ, Crim W, Jayaraj A. Optimal sizing of iliac vein stents. Phlebology. 2018;33 (7): 451-457. DOI: 10.1177 / 0268355517718763 . 